\title{
Digital public sphere: weaknesses and challenges
}

\author{
Helena Sousa, Manuel Pinto, Elsa Costa e Silva
}

Despite the conceptual difficulties and complex configuration, the concept of public sphere has dominated much of the recent literature in areas such as political sciences, cultural studies, communication sciences and sociology of new media. A space that establishes and organizes the relationship between the state and the civil society, the public sphere refers to the field of public interest where citizens seek to guide the exercise of power. Since its original proposition by Habermas (1968/1989) to more contemporary settings that include a media ecology punctuated by the internet, the concept has been subject to confrontations that seek to highlight its potential, but also its limitations, namely the unreal equality of participation and universal access.

In spite of criticisms and limitations, the Jürgen Habermas' understanding of public sphere has therefore remained a seminal concept within the scientific reflections on the conditions of democratic functioning of societies, as well as on the role of media in the promotion of deliberation and confrontation of alternatives. The original distinction between the public sphere and the private domain has lost sharpness, but it is still considered to be a structural idea, yet accommodating new frontiers. Also the rationality that is implicit to the argumentation and debate has lost the exclusivity of discursive practices, thus incorporating new modalities ranging from satire to humor, also including irony and sometimes with speeches approaching incivility.

Inseparable from the public sphere since its early conceptualization, the media are central to the public debate, both in its more traditional forms as through new modalities enhanced by digital technologies. The transformation of the mass media paradigm introduces clear changes in terms of media practices and in the role of citizens / consumers / producers. New media, particularly the Internet, pose new theoretical, methodological and practical challenges to the constitution of a digital public sphere. The conventional spaces devoted to public discussion are faced with various forms of socialization, with networking organizations and with new channels of dissemination and exchange of information, that update 'old' issues in terms of power, control and citizen participation.

Will there be in the Internet a space for the constitution of a public sphere, aggregating wills, arguments, positions, defenses, consensus? Or is the Internet a place of hopeless fragmentation where it is impossible to fit in and accommodate the interests of collective nature? These concerns do not have an obvious answer, which is obscured by the novelty of many of these new processes and by the complexity of the phenomenon. This difficulty does not, however, prevent intellectually exploring of the potential of the internet as a prospective promoter of a public sphere (Dahlgren, 2005). The level and types of political participation of citizens, an indefectible condition to the constitution of the public sphere, are being challenged by these new technologies and the limitations to 
the concept of the public sphere cannot be an impediment to the questioning of its consequences. Holding a pessimistic or an optimistic view of the potential of the internet, there is no doubt that these new technologies entail a paradigm shift with regard to our notions of politics and society (Charles, 2012).

Democracy, as a historical phenomenon, should be de-naturalized so that it is possible to conceive a model that incorporates the transformation of contemporary societies. Democracy is based on a problematic pillar, the civic participation, also an historical concept that is subject to the contingencies of the social interaction that shape it and challenge it. Citizens participate less and less in formal democratic mechanisms like elections, thus showing a political withdrawing or disengagement. Putnam (1995) speaks of a certain erosion of trust in social institutions to conclude for a decline of social capital, a term that designates the social networks and norms of reciprocity that are the cement of democracy and societies.

This narrative is confronted, on the other hand, by the existence of other forms of politics, non-party, non-organizational. The realm of politics is transmuting itself, leaving the corridors of the party headquarters, the parliaments, the ministerial offices. The notion of politics is widening, including new modes of participation and negotiation, with variable impacts. Contrary to the parliamentary and representative politics, the requirement for consistency or for a declared ideological canon does not stand - this is the domain of humorous satire, of the lyrics of hip-hop songs, fictional series or blogs and facebook pages.

These new civic identities emerge linked to new ideologies, disconnected from political parties, and this take us to consider that the new media - increasingly ingrained in our daily lives - may foster social relationships of a political nature. But unrestrained optimism must be stopped or at least contextualized with the reality of the network that, at the moment, presents more opportunities for consumption and entertainment than for political practices. The reality of the network is also of the increasing surveillance of users, marketization and utilization of data profiles (Dean, 2010). The nature of the network is a design thought by corporate interests, by large private companies, listed on stock-exchange and valued at millions.

The logic of the network can also be the "like-minded" one, driven by the logic of "likes" that does not expose to confrontation or diversity. The logic of the network is the struggle for attention, given the growing proliferation of websites, opportunities, which contrasts with an increasingly "googlerized" practice that leads the "most viewed" to be increasingly more visited - the "Googlerarchy" - while confining to the dark obscurity of the network all the other contributions that could make this a plural public sphere .

The fact that new tools are available on the internet does not mean that they are being used for a more participatory citizenship or for an empowerment of the new content producers of the network. Structural organizational forms of the society, namely the mainstream media, continue to be central agents of communication and information, as well as the major producers of the content consumed online. Thus, the Internet as a digital public sphere places scientific thought and research in front of various paradoxes. 
The aim of this issue of Communication and Society journal is to recognize and point out the virtues and the limits of a digital public sphere.

The methodological experiences that inform the articles of this journal are diverse, showing that approaches to this phenomenon require openness to different methods of analysis. In two articles, the authors use surveys to research the practices of users and, in two others, the researchers analyze these practices by qualitative analysis, looking to the contributions to news sites, particularly to the comments users produce. It is also possible to assess the digital public sphere through the critical analysis of blogs or thinking, in terms of its design, on its ontology. These are the proposals of the contributors of this issue.

Micheline Frenette and Marie-France Vermette offer a comparative analysis of young adults from different countries and their participation in the digital public sphere. By the application of a survey to university students in Canada, France, Sweden and Mexico, the authors highlight that it is necessary to contextualize the analysis, since different social and political frameworks originate different levels of participation. They conclude for the non-existence of a single profile of participation in terms of young adults - contrary to what some literature seems to assume.

Also using the survey, Santiago Giraldo Luque, Juan Francisco Martínez Cerdá and Maria Oralia Sanchez Paredes propose a critical analysis of the media practices of the Spanish people in what concerns the $15 \mathrm{M}$ movement, the 'Indignados' movement. In order to understand the spread of information through social networks, the authors conducted a survey of Internet users, which demonstrated the central importance of traditional media and the still limited user generated content.

Marisa Torres da Silva choses a qualitative analysis of the comments produced in two online Portuguese news media to investigate the quality of public deliberation. Demonstrating that, despite the potential they enfold, most of the comments to news are distant from the paradigm of Habermas' critical-rational deliberation, the author notes that this space may provide dialogue and reciprocity between the public of traditional media.

Looking at comments in a Finnish newspaper, Kim Standberg and Janne Berg arrive at very similar conclusions about the ambivalence of this participation mechanism. The level of justification presented by readers for the opinions expressed and logical reasoning that underlies it is only sufficient (on a scale constructed with measurable indicators proposed by the authors). There are also some failures in terms of reciprocity and of negative interactions, the authors concluding that comments can provide a platform for democratic conversations, but also for soapboxes.

The approach of Maria Francesca Murru is the analysis of the categories of the public in order to research on how the new modalities of interaction enhanced by online technologies have helped to empower new civic practices. Her object of study is the Italian blog Beppe Grillo, a comedian who has recently become a phenomenon in the field of Italian politics, particularly after the elections. Studying a sample of texts, the author points that this space was not a democratizing media because it rejected the potential of participatory and interaction of the digital technology. 
Finally, Pedro Andrade proposes an ontology of the digital public sphere, characterizing the transition from the web 2.0 to a new configuration, the web 3.0, inhabited by virtual places that include not only information, but essentially knowledge. This is, the author points out, a prerequisite for the construction of the digital public sphere, which is based on a citizenship capable of producing knowledge in a participatory manner. /

Translated by the authors

\section{REFERENCES:}

Charles, A. (2012). Interactivity: new media, politics and society, Oxford: Peter Lang.

Dahlgren, P. (2005). 'The Internet, public spheres, and political communication: dispersion and deliberation', Political Communication 22: 147-162.

Dean, J. (2010). Blog theory-feedback and capture in the circuits of drive, Cambridge/Malden: Polity Press.

Habermas, J. (1989). The Structural Transformation of the Public Sphere, Cambridge: MIT.

Putnam, R. D. (1995). 'Bowling Alone: America's declining social capital', Journal of Democracy 6 (1): 65-78./ 